\title{
Estimates of the current global population size and historical trajectory for sperm whales
}

\author{
Hal Whitehead ${ }^{1,2, *}$ \\ ${ }^{1}$ Department of Biology, Dalhousie University, Halifax B3H4JI, Nova Scotia, Canada \\ ${ }^{2}$ Max Planck Institute for Behavioural Physiology, PO Box 1564, 82305 Starnberg, Germany
}

\begin{abstract}
Assessments of sperm whale Physeter macrocephalus abundance based on invalid analyses of whaling data are common in the literature. Modern visual surveys have produced population estimates for a total of $24 \%$ of the sperm whale's global habitat. I corrected these assessments for whales missed on the track line and then used 3 methods to scale up to a global population. Scaling using habitat area, plots of 19th century catches and primary production produced consistent global population estimates of about 360000 whales $(\mathrm{CV}=0.36)$. This is approximately $20 \%$ of the numbers reproduced in current literature from invalid whaling-based estimates. A population model, based on that used by the International Whaling Commission's Scientific Committee, and which considers uncertainty in population parameters and catch data, was used to estimate population trajectories. Results suggest that pre-whaling numbers were about 1110000 whales (95\% CI: 672000 to 1512000 ), and that the population was about $71 \%$ (95\% CI: 52 to $100 \%$ ) of its original level in 1880 as open-boat whaling drew to a close and about $32 \%$ (95\% CI: 19 to $62 \%$ ) of its original level in 1999, $10 \mathrm{yr}$ after the end of large-scale hunting. Thus, widely held views about the status of sperm whale populations need considerable revision.
\end{abstract}

KEY WORDS: Sperm whale $\cdot$ Physeter $\cdot$ Population $\cdot$ Depletion $\cdot$ Whaling

\section{INTRODUCTION}

The sperm whale Physeter macrocephalus, the largest of the odontocetes or toothed whales, is a deep diver found over almost all deep (>1000 m) ice-free waters of the globe (Rice 1989). Because of its size, wide distribution, and presumed numbers it is thought to be an important element in mesopelagic ecosystems (e.g. Clarke 1977, Katona \& Whitehead 1988). The sperm whale has been the subject of 2 large-scale and economically significant periods of hunting (Starbuck 1878, Tønnessen \& Johnsen 1982; Fig. 1). 'Open-boat' whaling for sperm whales which began in 1712, peaked in about 1830, and continued into the 1920s, was one of the foremost industries of the late 18th and early 19th centuries. 'Modern' whalers with enginepowered whaling vessels, harpoon guns and other

*E-mail: hal.whitehead@dal.ca technological aids, first attacked sperm whales in the early 20th century, although sperm whales were not a major target until the 1950s. Modern sperm whaling was particularly intense during the 1960s after the decline of most baleen whale populations. However, due to the International Whaling Commission's moratorium on commercial whaling and for other reasons, sperm whaling had virtually ended by 1988 .

Despite great commercial and scientific interest in the species, there has been no valid population estimate, globally or for any ocean basin. Thus we have no real concept of the effects of the hunts on sperm whale populations.

In the late 1970s and early 1980s the Scientific Committee of the International Whaling Commission, with the hope of better managing exploitation, put considerable effort into assessing sperm whale populations. Initially, the Committee used catch-per-unit-effort methods (e.g. Ohsumi 1980). However, there were many problems when applying these techniques to modern 


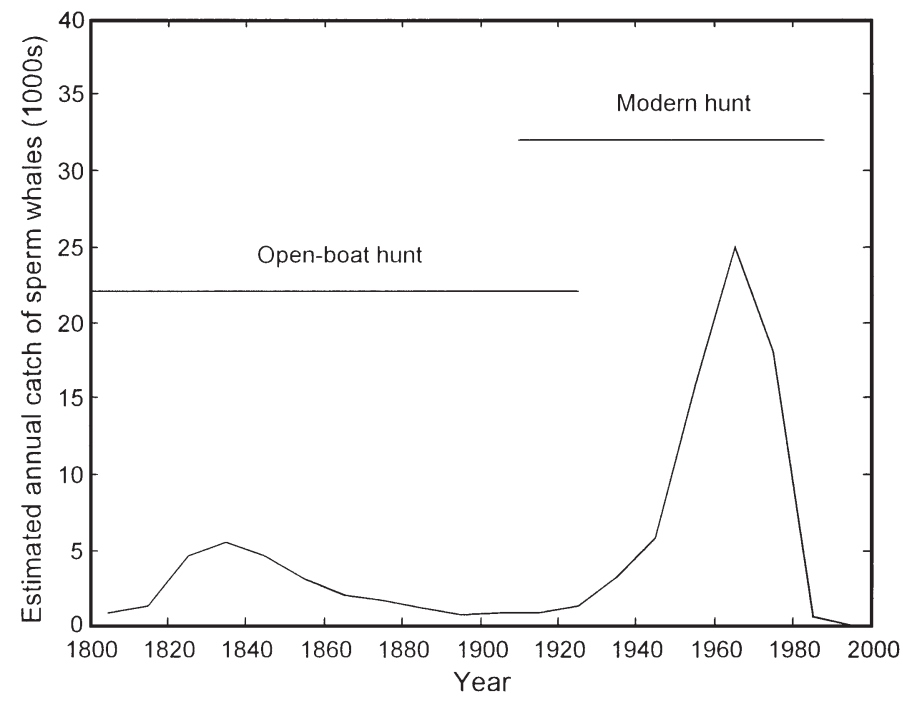

Fig. 1. Physeter macrocephalus. Sperm whale catches from 1800 to 1999 (from Best 1983 and FAO Fisheries Department, Fishery Information, Data and Statistics Unit. FISHSTAT Plus: Universal software for fishery statistical time series. Version 2.3. 2000). The open-boat hunt began in 1712 and catches from it may be under-estimated here (Best 1983)

sperm whaling data, including recruitment and mortality (Cooke 1986), temporal trends in the practice of whaling (Horwood 1980, Smith 1980), whale movements (Cooke 1986), grouping of whales (Allen 1980), multiple-species hunts, and falsification of data (Zemsky et al. 1995). Consequently, assessment of sperm whale populations by catch-per-unit-effort methodology was virtually discontinued in the early 1980's (Tillman \& Breiwick 1983).

Attention then turned to complex age-specific, and especially length-specific, techniques (e.g. Cooke \& de la Mare 1983), in which changes in length or age distributions indicated the degree of depletion of the stock. Although less problematic than catch-per-unit-effort methods, some difficulties persisted. These included falsified data (Best 1989) and movements of the whales (Cooke 1986, Whitehead 2000). There were also new challenges such as the need for accurate aging (for agespecific methods) or an accurate age-length key (for length-specific methods). After a few years of hard work, it became apparent that these techniques were also unable to give reliable estimates (Cooke 1986), and with the decline of the sperm whaling industry the Scientific Committee of the International Whaling Commission turned their attention elsewhere.

Unfortunately, despite the acknowledgments by those involved in these assessments (e.g. Cooke 1986), invalid estimates of sperm whale populations using catch- per-unit-effort or length-specific methods made their way into reviews of sperm whale biology (e.g. Gosho et al. 1984, Rice 1989). From there, these esti- mates propagated into more general literature (e.g. Evans 1987, Berta \& Sumich 1999, Bowen \& Siniff 1999). Reports of current global population sizes of about 1.5 to 2 million whales, constituting 65 to $85 \%$ of the original populations, (Evans 1987, Berta \& Sumich 1999, Bowen \& Siniff 1999) which originated in the catch-per-unit-effort or length-specific methods of the Scientific Committee of the International Whaling Commission are of very questionable validity.

In recent years, the abundance of sperm whale populations have been estimated over scales of less than an ocean basin using 3 principal techniques: markrecapture techniques applied to photographic identifications (e.g. Childerhouse et al. 1995, Whitehead et al. 1997), acoustic censuses (e.g. Leaper et al. 1992, Davis \& Fargion 1996, Barlow \& Taylor 1998), and visual censuses from ships or aircraft (Table 1). Although markrecapture analyses of photoidentifications and acoustic censuses have considerable promise for estimating sperm whale abundance, they have only been used occasionally, and the great majority of reasonably valid sperm whale population estimates come from visual censuses. Visual censuses of cetaceans and other animals pose a number of methodological challenges, but, fortunately, there is a standard and well-developed methodology (Buckland et al. 1993) which is generally used. The principal remaining difficulty with most of the estimates of sperm whale populations is that they have not been corrected for the whales not counted because they were underwater as the censusing ship or aircraft passed. The probability that an animal on the transect line is sighted, referred to as $g(0)$, is usually assumed to be 1 . Due to their long dives (Papastavrou et al. 1989, Watkins et al. 2002), this is plainly false for sperm whales.

Here I use available visual censuses for sperm whales, make a correction for $g(0)$, and then extrapolate to a global population estimate. I try to scale up from the areas that have been surveyed to the global sperm whale habitat using 3 alternative assumptions: that sperm whale densities are similar in areas that have and have not been surveyed; that sperm whale density in any area is roughly proportional to the number of whales killed in the area by open-boat whalers (see Whitehead \& Jaquet 1996 for a justification of this); or that sperm whale density in any area is roughly proportional to primary productivity. The latter is justified by the transfer of energy up the food chain, so that, over large spatial and temporal scales, regions with higher primary production generally possess more sperm whales (Gulland 1974, Jaquet 1996, Jaquet et al. 1996). This global estimate of current sperm whale abundance is then used, together with other information on the population biology of the whales and estimates of removals by whalers, to pro- 


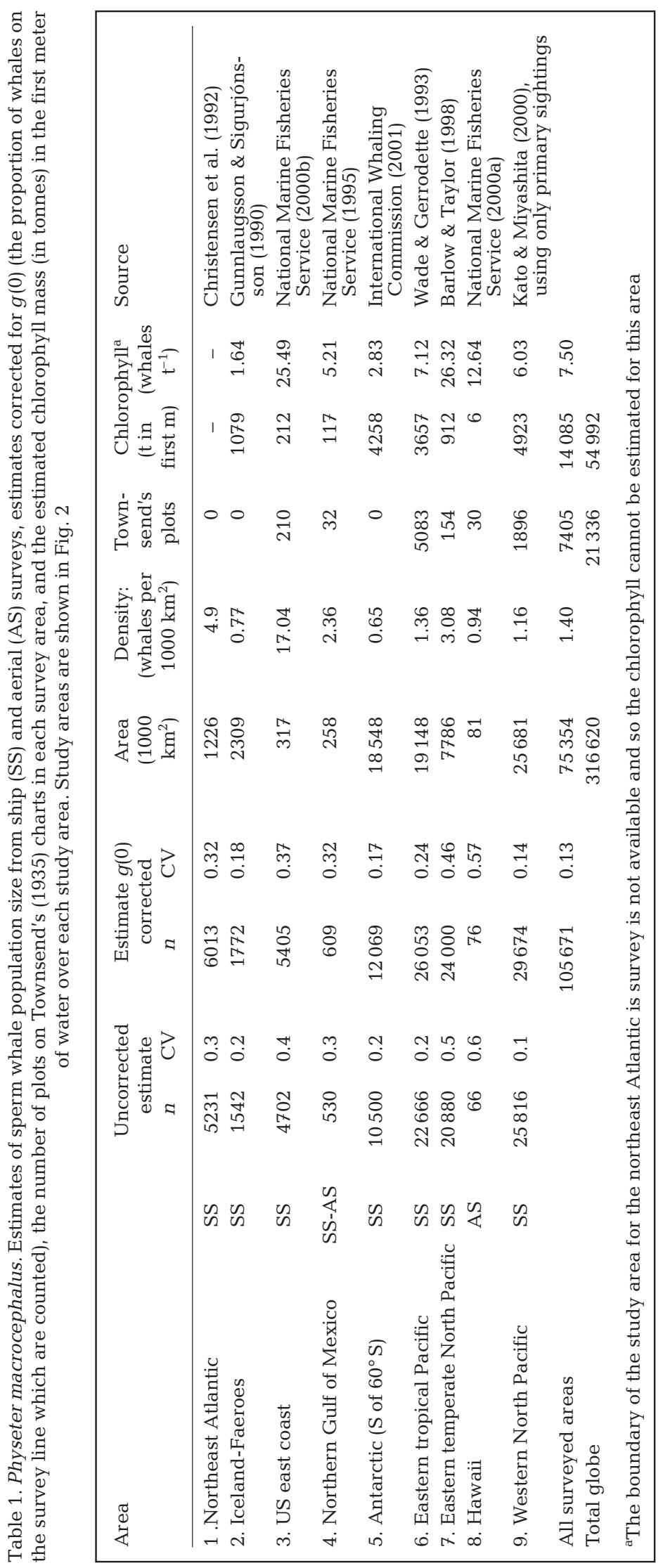

duce plausible trajectories of global sperm whale populations since the start of commercial whaling in 1712 .

\section{MATERIALS AND METHODS}

Estimation of current global sperm whale population size. The 9 estimates of sperm whale population size of which I am aware that result from either ship or aerial visual surveys are listed in Table 1. Estimates superseded by later work with increased sampling effort in the same area or better methodology applied to the same data are excluded. The surveyed areas, which have virtually no overlap, are shown in Fig. 2. Together the surveys cover $75.4 \times 10^{6} \mathrm{~km}^{2}$, about $24 \%$ of the surface of the ocean which is greater than $1000 \mathrm{~m}$ deep and less than $70^{\circ}$ latitude (i.e. excluding the frozen Arctic Ocean), primary sperm whale habitat (Rice 1989). All the surveys, except 2 of the smallest, were from ships rather than aircraft.

Most survey assessments did not correct for $g(0)$, the whales missed because they were under water when the surveyors passed. Even where corrections were applied, the uncorrected values are given in the third column of Table 1. Of the surveys which did correct for $g(0)$, the best supported correction is that of Barlow \& Taylor (1998), who used a methodology which incorporates the radial distribution of detection distances and the diving behavior of the whales. Thus, I have used their estimate of $g(0)=0.87$ $(\mathrm{CV}=0.09)$ to correct all the estimates of sperm whale abundance in Table 1. Barlow \& Taylor (1998) consider that their estimate of $g(0)$ is not fully justified for their own survey, and it is likely to be even less valid for the other surveys. It is almost certainly too large for the aerial surveys, as the faster travel of the observers will lead to a greater proportion of diving whales being missed, biasing these estimates downwards. However, the aerial surveys only represent $0.1 \%$ of the ocean area covered by the surveys listed in Table 1 and Barlow \& Taylor's (1998) estimate of $g(0)$ is the best available. CVs for the $g(0)$ corrected estimates, given in Table 1, were calculated by combining the $\mathrm{CV}$ of the uncorrected abundance estimate (Column 4 of Table 1) and the $\mathrm{CV}$ of the estimate of $g(0)$ :

$$
\mathrm{CV}\left(n_{i}\right)=\sqrt{\mathrm{CV}\left(n_{i}{ }^{\prime}\right)^{2}+\mathrm{CV}(g(0))^{2}}
$$

where $n_{i}{ }^{\prime}$ is the uncorrected population estimate for area $i$, and $n_{i}$ is the corrected population estimate for area $i$. 


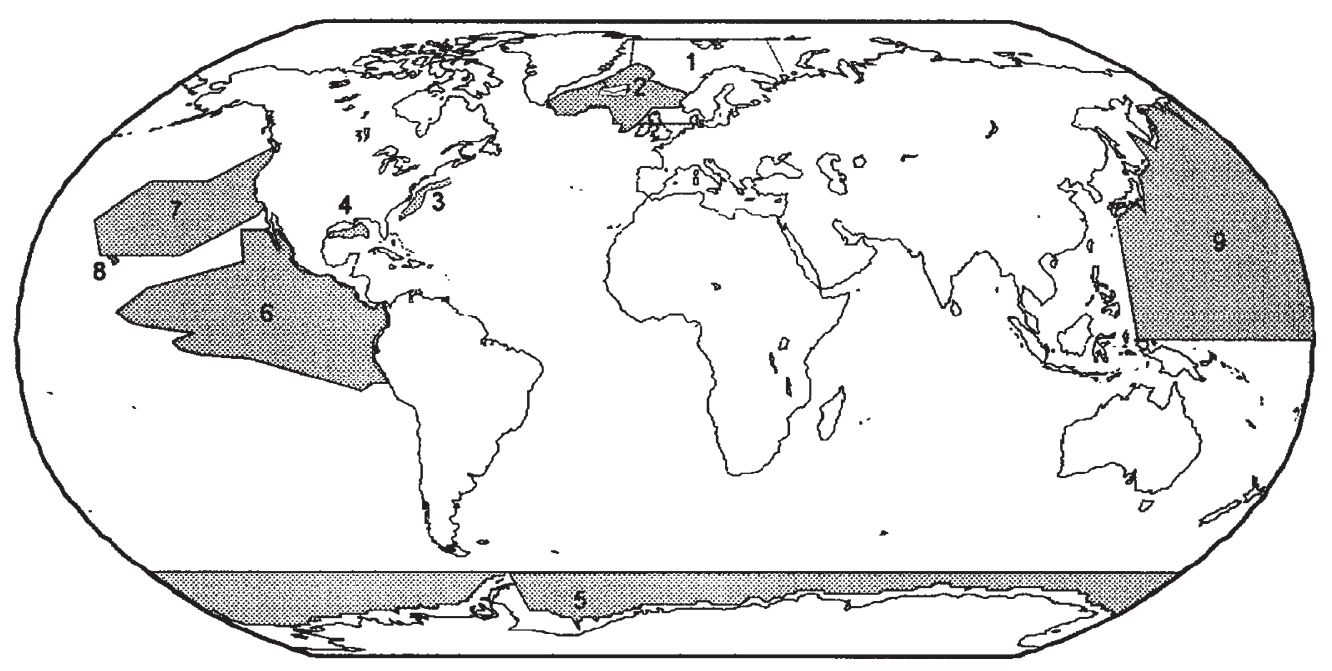

Fig. 2. Study areas for which there is a sperm whale population estimate from ship or aerial surveys (listed in Table 1). The boundary of the survey area in the northeast Atlantic off Norway is not available so its rough location is indicated by a line. Studies are labeled by numbers as in Table 1

Densities (whales per $1000 \mathrm{~km}^{2}$ ) could then be calculated for each survey area using the $g(0)$-corrected estimates. An estimate of the population size in all the surveyed areas combined, $n_{\mathrm{T}}$, was then obtained by summing the $g(0)$-corrected estimates for each survey area:

$$
n_{\mathrm{T}}=\sum n_{i}
$$

The CVs for the corrected population estimates were combined to produce a CV for the estimate for all areas:

$$
\operatorname{CV}\left(n_{\mathrm{T}}\right)=\sqrt{\frac{\sum\left(\mathrm{CV}\left(n_{i}\right) n_{i}\right)^{2}}{\sum n_{i}}}
$$

This population estimate for the surveyed areas combined was then extrapolated to the global habitat of the sperm whale using 3 techniques:

(1) Scaling by area. In this I assume that the ocean areas $\left(>1000 \mathrm{~m}\right.$ deep and $<70^{\circ} \mathrm{N}$ ) not covered by the surveys have the same average density of sperm whales as those that were surveyed.

(2) Scaling by catches marked in Townsend's (1935) charts of the positions in which 19th century US whalers made their kills of sperm whales. This assumes that the current density of sperm whales in any area is proportional to the number of days on which catches were made in any area as represented on the charts. Whitehead \& Jaquet's (1996) simulations suggest that this should be approximately true. The total number of sperm whale plots on Townsend's (1935) charts, 21336 , is from Best (1983).

(3) Scaling by primary productivity. Sperm whale abundance seems related, over broad scales, to primary productivity (Jaquet et al. 1996). The estimated surface chlorophyll (tonnes per meter depth) was calculated for each of the study areas and for all the oceans suitable for sperm whales (>1000 m deep, and south of $70^{\circ} \mathrm{N}$ ) using estimates of chlorophyll mass at the surface per meter depth by NOAA (www.nodc. noaa.gov/ocs/data_woa.html).

Global estimates of sperm whale populations were then:

$$
N=n_{\mathrm{T}} \frac{X}{\sum x_{i}}
$$

where $x_{i}$ is the amount of the scaling factor (area, plots on Townsend's charts, or chlorophyll) in survey area $i$, and $X$ is the amount in all sperm whale habitat. Coefficients of variation for $N$ were calculated from:

$$
\mathrm{CV}(N)=\sqrt{\mathrm{CV}\left(n_{\mathrm{T}}\right)^{2}+\mathrm{CV}\left(n_{i} / x_{i}\right)^{2}}
$$

No coefficient of variation for $N$ could be calculated for extrapolation method (2), as some of the survey areas at high latitudes had no plots on Townsend's charts. Thus, $x_{i}=0$ and $n_{i} / x_{i}=\infty$, rendering $\mathrm{CV}\left(n_{i} / x_{i}\right)$ meaningless.

Population trajectory. A simple population model, based on the approach used by the Scientific Committee of the International Whaling Commission (International Whaling Commission 1982), was used to examine possible trajectories of the global sperm whale population following the start of commercial whaling in 1712.

The model considers 2 areas, the Atlantic and Pacific/ Indian Oceans, between which there is assumed to be little interchange. This seems to be true for females, although possibly not for all males (Lyrholm et al. 
1999). This division is made because commercial sperm whaling started in the Atlantic about $85 \mathrm{yr}$ before it progressed into the other 2 oceans but the profile of exploitation was likely quite similar in the Pacific and Indian Oceans (Wray \& Martin 1983).

There are usable catch data available from 1800 to 1999 (Fig. 1), although these may be biased downwards in some cases (Best 1983, Zemsky et al. 1995). However, there is a gap between 1712, when commercial sperm whaling started in the Atlantic, and 1800, when hunting was beginning to move into the Pacific and Indian Oceans.

In year $y$, let $n(A, y)$ be the population of sperm whales in the Atlantic Ocean, and $n(P, y)$ the population in the Pacific and Indian Oceans, so that $n(., y)$ is the global population $[n(., y)=n(A, y)+n(P, y)]$. If $p_{\mathrm{A}}$ is the proportion of the global sperm whale population in the Atlantic before whaling, $q_{\mathrm{A}}$ gives the relative depletion of Atlantic population in 1800, $c(y)$ is the reported global catch of sperm whales in year $y$ (as in Fig. 1), and $d(y) \times c(y)$ the actual catch (so that $d$ corrects for underreporting), then:

$$
\begin{aligned}
& n(A, 1800)=p_{\mathrm{A}} \times\left(1-q_{\mathrm{A}}\right) \times n(., 1712) \\
& n(P, 1800)=\left(1-p_{\mathrm{A}}\right) \times n(., 1712)
\end{aligned}
$$

and for $y>1800$ :

$$
\begin{aligned}
n(A, y)= & {\left[N(A, y-1)-d(y) \times c(y) \times \frac{n(A, y-1)}{n(., y-1)}\right] \times } \\
& {\left[1+r \times\left(1-\frac{n(A, y-1)}{p_{\mathrm{A}} \times n(., 1712)}\right)^{1+b}\right] } \\
n(P, y)= & {\left[N(P, y-1)-d(y) \times c(y) \times \frac{n(P, y-1)}{n(., y-1)}\right] \times } \\
& {\left[1+r \times\left(1-\frac{n(P, y-1)}{\left(1-p_{\mathrm{A}}\right) \times n(., 1712)}\right) 1+b\right] }
\end{aligned}
$$

where $r$ is the maximum potential rate of increase of sperm whale populations, and $b$ the density-dependent exponent, which describes how rates of increase vary with relative population size. The actual rate of increase at any population size $n$ is given by $r \times$ $[1-n / n(0)]^{1+b}$, where $n(0)$ is the population size before exploitation $\left(p_{\mathrm{A}} \times n(., 1712)\right.$ and $\left(1-p_{\mathrm{A}}\right) \times n(., 1712)$ for the Atlantic and Pacific/Indian Oceans).

For any choice of population and exploitation parameters $\left[n(., 1712), p_{\mathrm{A}}, r, b,\{d\}, q_{\mathrm{A}}\right]$ a population trajectory can be calculated, giving a current population size, $n(., 1999)$. In practice, there is information on the population in 1999, from the first part of this paper, but not in 1712. Thus for any set of the other parameters, and a value of $n(., 1999)$, an estimate of $n(., 1712)$ was found (using the 'fmins' function of MATLAB5.3) so that the trajectory reached $n(., 1999)$ in 1999 . If no trajectory using the other randomly selected parameters reached the chosen $n(., 1999)$, then the parameters were discarded and a new set chosen. Consequently, for a set of $\left[n(., 1999), p_{\mathrm{A}}, r, b,\{d\}, q_{\mathrm{A}}\right]$, the model produces a trajectory and value of $n(., 1712)$ from which degrees of depletion and other measures can be calculated.

There is considerable uncertainty about most of the input parameters for this model. Thus it was run with both the 'best' parameters, and sets of parameters chosen from within a 'reasonable range' using the uniform distribution, unless noted. These were:

Proportion of sperm whales in Atlantic before modern whaling: best $p_{\mathrm{A}}=33 \%$; reasonable range 25 to $40 \%$ (as $25 \%$ of waters $>1000 \mathrm{~m}$ deep are in the Atlantic; $33 \%$ of surface chlorophyll in Atlantic; and $33 \%$ of plots on Townsend's charts in Atlantic; Best 1983).

Reduction in Atlantic population 1712 to 1799: best $q_{\mathrm{A}}=33 \%$; reasonable range 10 to $55 \%$. There is little information on this, but many whalers certainly perceived that the Atlantic sperm whales were substantially depleted when they moved operations into the other oceans in about 1800 (e.g. Starbuck 1878).

Maximum rate of increase: best $r=1.1 \%$; reasonable range 0.7 to $1.5 \%$. The population parameters used by the International Whaling Commission (1982) suggest $r=0.9 \%$ for a population with stable age distribution, but these include very uncertain, and probably overestimated, mortality rates, and no changes with age in either fecundity or adult mortality. It may be more realistic to use the well-established mortality schedule of killer whales (Orcinus orca; Olesiuk et al. 1990) and an age-specific pregnancy rate taken from the data presented by Best et al. (1984; pregnancy rate for mature females $=0.257-0.0038 \times$ Age in years), in which case the annual rate of increase with stable age distribution is $1.1 \% \mathrm{yr}^{-1}$.

Density-dependent exponent: best $b=1.4$ (International Whaling Commission 1982); reasonable values chosen randomly from $\{0,0.5,1.4,6,100\}$, as there is no empirical data on its real value.

Correction for open-boat catch: There are a number of reasons why the estimates of open-boat catch shown in Fig. 1, which were calculated from oil production, may be underestimates, including catches by non-US and British whalers, whales caught but not processed, and wrecked whaling ships, but the scale of this underestimate is unclear (Best 1983). Thus the catches from 1800 to 1910 are corrected by a factor of $d=1.5$ (reasonable range 1.1 to 3.0 ).

Correction for modern catch: There are also inaccuracies of reporting in the modern hunt (Zemsky et al. 1995, Kasuya 1999). Figures presented by Zemsky (1995) suggest under-reporting by at least $16 \%$ in Soviet Antarctic pelagic whaling for sperm whales. It is 
not clear whether such levels were common in other modern sperm whaling operations, and in some circumstances there may have been over-reporting (e.g. Kasuya 1999). Thus the catches from 1910 to 2000 are uncorrected $(d=1.0)$ but a reasonable range for $d$ during this period was taken to be 0.9 to 1.2 .

Population in 1999: best $n(., 1999)=360000$, reasonable range chosen from normal distribution with mean 360000 and $\mathrm{CV}=0.36$, from the earlier part of this paper.

From each run of the model, 3 trajectory measures were calculated: the pre-exploitation level $[n(., 1712)]$, and the relative levels of the population in 1880 and $1999[n(., 1880) / n(., 1712), n(., 1999) / n(., 1712)]$. By discarding the 25 lowest and 25 highest values of each measure from the 1000 random runs, approximate $95 \%$ confidence intervals were obtained. Sensitivities were calculated by correlating each input parameter with the 3 output measures.

\section{RESULTS}

\section{Densities}

The estimated mean density of sperm whales in the surveyed areas was $1.4 \times 10^{-3}$ whales $\mathrm{km}^{-2}(\mathrm{CV}=0.13)$, but there was considerable variation in sperm whale density between areas, ranging from a high in the western North Atlantic between the edge of the continental

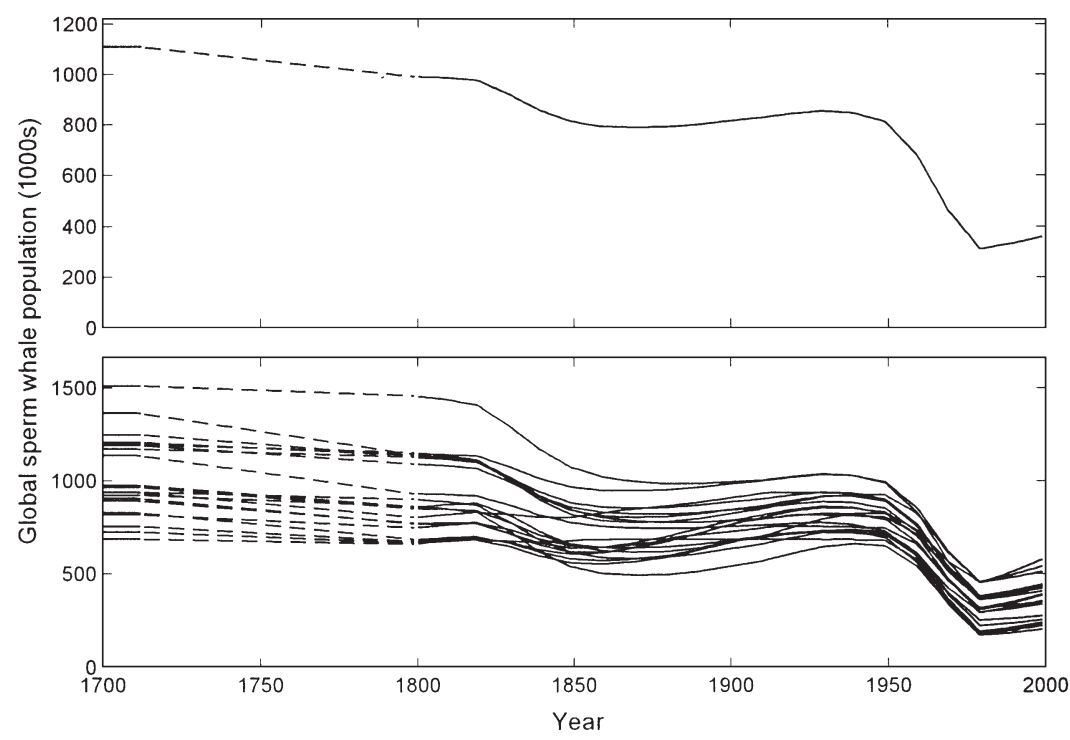

Fig. 3. Physeter macrocephalus. Estimated population trajectories for the global sperm whale population from 1700 to 1999. The upper plot shows the trajectory calculated from my best estimate of the population and model parameters, the lower plot shows 20 trajectories calculated using randomly chosen parameters within reasonable ranges. The period from 1712 to 1800 is dashed as information about this time period is very limited shelf and the Gulf Stream of $17 \times 10^{-3}$ whales $\mathrm{km}^{-2}$ to a low in the Antarctic of $0.65 \times 10^{-3}$ whales $\mathrm{km}^{-2}$.

\section{Abundance}

There were an estimated total of 105670 sperm whales $(\mathrm{CV}=0.13)$ in the surveyed areas combined. These were extrapolated into global population estimates as follows:

(1) $N=452000$ sperm whales $(\mathrm{CV}=0.53)$, scaling by area;

(2) $N=304500$ sperm whales, scaling by plots on Townsend's charts;

(3) $N=361400$ sperm whales $(\mathrm{CV}=0.36)$, scaling by primary production.

It is encouraging that the 3 estimates are fairly similar with overlapping CVs. Of the 3, that obtained by scaling from primary productivity (3) appears the most precise as it has the lowest CV. This is indicated by the smallest variation among study areas in the density columns of Table 1. It is also intermediate between the other estimates.

\section{Trajectory}

The reconstructed trajectory of the global sperm whale population from 1700 to 1999 using the 'best' estimates of the population parameters is shown in the upper part of Fig. 3. As an indication of uncertainty in this reconstruction, 20 runs using randomly selected parameters from within reasonable ranges are displayed beneath. There is clearly much uncertainty in how global sperm whale populations have risen and fallen with whaling pressure. However, some generalities do emerge.

The initial population size seems to have been about 1110000 whales (approximate $95 \%$ confidence interval 672000 to 1512000 ; Table 2). The open-boat hunt appears to have reduced the population to about $71 \%$ of its original value (approximate 95\% confidence interval 52 to $100 \%$ ) of its original level in 1880. The population seems to have recovered somewhat from 1870 to 1940 with diminished catches, but, except in a few runs, did not approach its unexploited level. Modern whaling's severity is clearly shown by the trajectories with populations declining dramatically from 1945 to 1975 . The model also indicates that the decline in sperm whaling in the late 1970s came just in time to prevent severe overexploitation. The 
model suggests that the current population is about $32 \%$ of its prewhaling value (approximate 95\% confidence interval 19 to $62 \%$ ). Using the current population estimates from scaling by area or Townsend's (1935) charts, rather than productivity, gives similar estimates of these population measures (Table 2).

The results of the sensitivity analysis (shown in Table 3) suggest that more accurate estimates of initial population will require better estimates of the maximum rate of increase, the density-dependent exponent, and the current population size. The estimate of depletion in 1880 is most dependent on the correction for the open-boat catches and the density-dependent exponent. The estimate of current depletion largely depends on current population size and the density-dependent exponent. In contrast, the input values of the proportion of sperm whales in the Atlantic in 1712, the reduction in the Atlantic population by 1800 and the correction for misreporting the modern catch have relatively little impact on the output measures. Overall then, improving the current population estimate will also give us a better idea of the historical trajectory of sperm whale populations, although to calculate an accurate trajectory of the global sperm whale population we also need more information on population parameters and 19th century catch rates.

\section{DISCUSSION}

\section{Current population size}

The global sperm whale population estimates calculated here should have more credibility than previous ones, as most sources of uncertainty are explicitly incorporated in the methodology used to analyze the original surveys, and scaling them up to a global estimate. However there are some potential biases and errors which were not fully considered in the model. As a consequence the global estimates may be more imprecise than is suggested by the calculated CVs. These include the estimate of $g(0)$ and calculation of mean group size in the original surveys (Barlow \& Taylor 1998).

To assess the potential for error in $g(0)$, consider the behavior of sperm whales. According to a range of sources (summarized by Whitehead 2003), sperm whales socialize about $25 \%$ of the time at the surface, and during the remainder of the $75 \%$ spent foraging dive for roughly $37.5 \mathrm{~min}$ with about $7.5 \mathrm{~min}$ at the surface. Thus, if $t$ min is the time period for which a sperm whale at the surface on the track line of the survey vessel is visible, then an estimate for $g(0)$ is:

$$
g(0)=0.25+\frac{0.75(7.5+2 t)}{37.5}=0.4+0.04 t
$$

As survey ships travel at about $18 \mathrm{~km} \mathrm{~h}^{-1}$ and can see sperm whales to about $3.6 \mathrm{~km}, t=12 \mathrm{~min}$ and $g(0)=0.88$, almost exactly Barlow \& Taylor's estimate. In an extreme case, the ship might travel at $25 \mathrm{~km} \mathrm{~h}^{-1}$ and see sperm whales to about $2.5 \mathrm{~km}$, so $t=6 \mathrm{~min}$ and $g(0)=$ 0.64 , which is only just outside 2 CVs of Barlow \& Taylor's estimate of $g(0)$. Therefore Barlow \& Taylor's estimate of the precision of their $g(0)$ is not unreasonable. Thus I suspect that additional error and biases from this and other unaccounted sources are reasonably small compared with the estimated CV in the global population estimate of 0.36 .

This CV itself is somewhat disappointingly large, principally the result of imperfect scaling up from the surveyed areas to the global habitat of the sperm whale. This is indicated by the wide variation in densities of sperm whales and numbers per tonne of chlorophyll in Table 1 . None of the 3 scaling measures that I 
have used predict sperm whale abundance particularly well. If a better scaling factor could be found, we would have a more precise global estimate.

Nonetheless, this current estimate of 360000 whales is considerably more valid than those that currently pervade the literature, for which precision and bias have not been able to be assessed. It appears that these estimates, in the range of 2 million or so whales worldwide (Evans 1987, Berta \& Sumich 1999), are optimistically large by a factor of about 5 . Consequently, ecological studies which require an estimate of global sperm whale numbers (e.g. Clarke 1977) need revision.

\section{Trajectory}

I have tried to incorporate uncertainty about the population biology and exploitation history of the sperm whale by the random choice of input parameters into the population model. However this is still a simplistic model and several potentially important factors are omitted.

One of the most important is geographical population structure. Although sperm whale populations show remarkably little population structure genetically (Lyrholm \& Gyllensten 1998) or in most other aspects of their biology (Dufault et al. 1999), hunting was not uniform across sperm whale habitat during the periods of exploitation. Thus there will have been relatively exploited and unexploited parts of the population with different rates of increase. The effects of averaging over sub-populations with different degrees of depletion will vary with the density-dependent response of the population (represented in the model used here by $b$ ). To provide an idea of the potential significance of such structuring on global population dynamics, I divided each of the 2 areas, Atlantic and Pacific/Indian oceans, into 2 separate equal-sized subpopulations, one of which was exploited first, with exploitation of the second not beginning until the first had been eliminated. Using the best estimates of the input parameters of the model the outputs were: population in 1712 of 1267000 (rather than 1110000 in the original runs with fully mixed populations in each ocean area), a population in 1999 of $28 \%$ of the initial value (rather than $32 \%$ ) and a population in 1880 of $74 \%$ (rather than $71 \%$ ). Thus, under this rather extreme scenario of population subdivision, outputs were little affected, indicating that the assumption of homogeneous exploitation of each ocean population does not critically affect the results of the modeling.

Other simplifications include a lack of explicit age structure in the population model, and the effects of whaling on social structure, and thus on the fitness of whales not killed (e.g. Botkin et al. 1980). These are most likely to be important in the consideration of modern whaling which was both more selective and more severe in its impact than the open-boat hunt. Together with other modern anthropogenic influences, such as fisheries by-catch (Haase \& Félix 1994), chemical pollution (Law et al. 1996, Nielsen et al. 2000) and noise, this may mean that the apparent recovery over the last 20 yr indicated in the trajectories of Fig. 3 may be optimistic.

The results of the model indicate that pre-whaling population levels were about one million, much less than the numbers of 2 to 3 million indicated elsewhere (e.g. Rice 1989). They also suggest that the current population is about $32 \%$ of the pre-whaling level and so considerably more depleted than the 65 to $85 \%$ levels which are reported elsewhere (Evans 1987, Berta \& Sumich 1999).

The trajectories suggest that the open-boat hunt did not have a very substantial effect on the global population, reducing it by perhaps 0 to $50 \%$ by 1880 (Table 2). This seems to conflict with reports of the 19th Century open-boat whalers that sperm whales were becoming substantially scarcer (e.g. Melville 1851), and reductions in sighting rates of about $60 \%$ from 1830 to 1850 off both the Galápagos Islands and in the northwest Pacific (Tillman \& Breiwick 1983, Whitehead 1995). The discrepancy between the severe drop in the sighting rates of the whalers over this period and the results of the model may be at least partially explained if the whales changed their schooling behavior or distribution as exploitation progressed, or if there were refuges, such as unavailable or undiscovered grounds, where the whales were fairly free from the whalers.

\section{Future prospects}

While this analysis shows that estimates of sperm whale current and historical abundance found in the literature are seriously inaccurate, there is still much uncertainty about population levels. As indicated by the sensitivity analysis, a more precise estimate of current numbers would also improve the historical trajectory. One way to increase precision would be to find a more effective scaling factor, but this may not be possible. Alternatively, precision would be improved by increasing the proportion of sperm whale habitat for which estimates are available. Acoustic censuses for this vocal species hold great promise (Leaper et al. 1992, Davis \& Fargion 1996, Barlow \& Taylor 1998), and it may be possible to automate acoustic censuses from ships of opportunity, thus providing wide coverage with relatively little cost, and so resulting in much more precise estimates of abundance for this species. 
Acknowledgements. I am very grateful to Jay Barlow for providing an unpublished manuscript and for comments on part of this work, as well as to 4 reviewers for useful suggestions for improvement. The research was funded by the Natural Sciences and Engineering Research Council of Canada.

\section{LITERATURE CITED}

Allen KR (1980) The influence of schooling behavior on CPUE as an index of abundance. Rep Int Whal Comm (Spec Issue) 2:141-146

Barlow J, Taylor BL (1998) Preliminary abundance of sperm whales in the northeastern temperate Pacific estimated from combined visual and acoustic surveys. Unpubl report to Scientific Committee of the International Whaling Commission SC/50/CAWS20

Berta A, Sumich JL (1999) Marine mammals. Evolutionary biology. Academic Press, San Diego

Best PB (1983) Sperm whale stock assessments and the relevance of historical whaling records. Rep Int Whal Comm (Spec Issue) 5:41-55

Best PB (1989) Some comments on the BIWS catch record data base. Rep Int Whal Comm 39:363-369

Best PB, Canham PAS, Macleod N (1984) Patterns of reproduction in sperm whales, Physeter macrocephalus. Rep Int Whal Comm (Spec Issue) 6:51-79

Botkin DB, Schimel DS, Wu LS, Little WS (1980) Some comments on density dependent factors in sperm whale populations. Rep Int Whal Comm (Spec Issue) 2:83-88

Bowen WD, Siniff DB (1999) Distribution, population biology and feeding ecology of marine mammals. In: Reynolds JE, Rommel SA (eds) Biology of marine mammals. Smithsonian Institution, Washington, DC, p 423-484

Buckland ST, Anderson DR, Burnham KP, Laake JL (1993) Distance sampling: estimating abundance of biological populations. Chapman \& Hall, New York

Childerhouse SJ, Dawson SM, Slooten E (1995) Abundance and seasonal residence of sperm whales at Kaikoura, New Zealand. Can J Zool 73:723-731

Christensen I, Haug T, Oien N (1992) Seasonal distribution, exploitation and present abundance of stocks of large baleen whales (Mysticeti) and sperm whales (Physeter macrocephalus) in Norwegian and adjacent waters. ICES J Mar Sci 49:341-355

Clarke MR (1977) Beaks, nets and numbers. Symp Zool Soc Lond 38:89-126

Cooke JG (1986) A review of some problems relating to the assessment of sperm whale stocks, with reference to the western North Pacific. Rep Int Whal Comm 36:187-190

Cooke JG, de la Mare WK (1983) Description of and simulation studies on the length-specific sperm whale assessment technique. Rep Int Whal Comm 33:741-745

Davis RW, Fargion GS (eds) (1996) Distribution and abundance of cetaceans in the north-central and western Gulf of Mexico, final report, Vol 2. US Department of the Interior, New Orleans

Dufault S, Whitehead H, Dillon M (1999) An examination of the current knowledge on the stock structure of sperm whales (Physeter macrocephalus) worldwide. J Cetacean Res Manag 1:1-10

Evans PGH (1987) The natural history of whales and dolphins. Facts on File, London

Gosho ME, Rice DW, Breiwick JM (1984) The Sperm Whale Physeter macrocephalus. Mar Fish Rev 46(4):54-64

Gulland JA (1974) Distribution and abundance of whales in relation to basic productivity. In: Schevill WE (ed) The whale problem. Harvard University Press, Cambridge, MA, p 27-51

Gunnlaugsson T, Sigurjónsson J (1990) NASS-87: Estimation of whale abundance based on observations made onboard Icelandic and Faroese survey vessels. Rep Int Whal Comm 40:571-580

Haase B, Félix F (1994) A note on the incidental mortality of sperm whales (Physeter macrocephalus) in Ecuador. Rep Int Whal Comm (Spec Issue) 15:481-483

Horwood JW (1980) Comparative efficiency of catcher boats with and without Asdic in Japanese pelagic whaling fleets. Rep Int Whal Comm (Spec Issue) 2:245-249

International Whaling Commission (1982) Report of the subcommittee on sperm whales. Rep Int Whal Comm 32: $68-86$

International Whaling Commission (2001) Report of the subcommittee on the comprehensive assessment of whale stocks-other stocks. J Cetacean Res Manag (Spec Issue) 3: 209-228

Jaquet N (1996) How spatial and temporal scales influence understanding of sperm whale distribution: a review. Mammal Rev 26:51-65

Jaquet N, Whitehead H, Lewis M (1996) Coherence between 19th century sperm whale distributions and satellitederived pigments in the tropical Pacific. Mar Ecol Prog Ser 145:1-10

Kasuya T (1999) Examination of the reliability of catch statistics in the Japanese coastal sperm whale fishery. J Cetacean Res Manag 1:109-122

Kato H, Miyashita T (2000) Current status of the North Pacific sperm whales and its preliminary abundance estimates. Paper presented to Scientific Committee of International Whaling Commission SC/50/CAWS2

Katona S, Whitehead H (1988) Are Cetacea ecologically important? Oceanogr Mar Biol Annu Rev 26:553-568

Law RJ, Stringer RL, Allchin CR, Jones BR (1996) Metals and organochlorines in sperm whales (Physeter macrocephalus) stranded around the North Sea during the 1994/1995 winter. Mar Pollut Bull 32:72-77

Leaper R, Chappell O, Gordon J (1992) The development of practical techniques for surveying sperm whale populations acoustically. Rep Int Whal Comm 42:549- 560

Lyrholm T, Gyllensten U (1998) Global matrilineal population structure in sperm whales as indicated by mitochondrial DNA sequences. Proc R Soc Lond B 265:1679-1684

Lyrholm T, Leimar O, Johanneson B, Gyllensten U (1999) Sexbiased dispersal in sperm whales: contrasting mitochondrial and nuclear genetic structure of global populations. Proc R Soc Lond B 266:347-354

Melville H (1851) Moby Dick or the whale. Penguin (1972), London

National Marine Fisheries Service (1995) Sperm whale (Physeter macrocephalus): northern Gulf of Mexico stock. Stock Assessment Report, Miami, p 127-129

National Marine Fisheries Service (2000a) Sperm whale (Physeter macrocephalus): Hawaiian stock. Stock Assessment Report, La Jolla, CA, p 217-220

National Marine Fisheries Service (2000b) Sperm whale (Physeter macrocephalus): North Atlantic stock. Stock Assessment Report, Woods Hole, MA, p 54-59

Nielsen JB, Nielsen F, Joergensen PJ, Grandjean P (2000) Toxic metals and selenium in blood from pilot whales (Globecephala melas) and sperm whales (Physeter catodon). Mar Pollut Bull 40:348-351

Ohsumi S (1980) Population assessment of the sperm whale in the North Pacific. Rep Int Whal Comm (Spec Issue) 2: $31-42$ 
Olesiuk P, Bigg MA, Ellis GM (1990) Life history and population dynamics of resident killer whales (Orcinus orca) in the coastal waters of British Columbia and Washington State. Rep Int Whal Comm (Spec Issue) 12: 209-243

Papastavrou V, Smith SC, Whitehead H (1989) Diving behaviour of the sperm whale, Physeter macrocephalus, off the Galápagos Islands. Can J Zool 67:839-846

Rice DW (1989) Sperm whale. Physeter macrocephalus Linnaeus, 1758. In: Ridgway SH, Harrison R (eds) Handbook of marine mammals, Vol 4. Academic Press, London, p $177-233$

Smith T (1980) Catches of male and female sperm whales by 2-degree square by Japanese pelagic whaling fleets in the North Pacific, 1966-77. Rep Int Whal Comm (Spec Issue) 2:263-275

Starbuck A (1878) History of the American whale fishery from its earliest inception to the year 1876. In: United States Commission on Fish and Fisheries, Report of the Commissioner for 1875-1876. Government Printing Office, Washington, Appendix A

Tillman MF, Breiwick JM (1983) Estimates of abundance for the western North Pacific sperm whale based upon historical whaling records. Rep Int Whal Comm (Spec Issue) 5: $257-269$

Tønnessen JN, Johnsen AO (1982) The history of modern whaling. University of California Press, Berkeley, CA

Townsend $\mathrm{CH}$ (1935) The distribution of certain whales as

Editorial responsibility: Otto Kinne (Editor),

Oldendorf/Luhe, Germany shown by the logbook records of American whaleships. Zoologica 19:1-50

Wade PR, Gerrodette T (1993) Estimates of cetacean abundance and distribution in the eastern tropical Pacific. Rep Int Whal Comm 43:477-493

Watkins WA, Daher MA, DiMarzio NA, Samuels A, Wartzok D, Fristrup KM, Howey PW, Maiefski RR (2002) Sperm whale dives tracked by radio tag telemetry. Mar Mammal Sci 18: $55-68$

Whitehead H (1995) Status of Pacific sperm whale stocks before modern whaling. Rep Int Whal Comm 45:407-412

Whitehead H (2000) Density-dependent habitat selection and the modeling of sperm whale (Physeter macrocephalus) exploitation. Can J Fish Aquat Sci 57:223-230

Whitehead H (2003) Sperm whales: social evolution in the ocean. University of Chicago Press, Chicago

Whitehead H, Jaquet N (1996) Are the charts of Maury and Townsend good indicators of sperm whale distribution and seasonality? Rep Int Whal Comm 46:643-647

Whitehead H, Christal J, Dufault S (1997) Past and distant whaling and the rapid decline of sperm whales off the Galápagos Islands. Conserv Biol 11:1387-1396

Wray P, Martin KR (1983) Historical whaling records from the western Indian Ocean. Rep Int Whal Comm (Spec Issue) 5: 218-242

Zemsky VA, Berzin AA, Mikhaliev YA, Tormosov DD (1995) Soviet Antarctic pelagic whaling after WWII: review of actual catch data. Rep Int Whal Comm 45:131-135

Submitted: February 28, 2002; Accepted: June 19, 2002

Proofs received from author(s): September 22, 2002 